\title{
Detection the Aflatoxins in FoodStuffs (Milk, Egg, Banana and Onion) from Three Locations (Khartoum, Omdurman and Bahri) in Khartoum State, Sudan
}

\author{
Anwar IAG1 ${ }^{1}$, Sabahelkhier $\mathrm{MK}^{1 *}$ and Babiker EE ${ }^{2}$ \\ ${ }^{1}$ Department of Biochemistry and Molecular Biology, Faculty of Science and \\ Technology, Sudan \\ ${ }^{2}$ Food Science and Nutrition Department, College of Food and Agricultural Sciences, \\ King Saud University, Saudi Arabia
}

\section{Research article \\ Volume 4 Issue 4}

Received Date: November 21, 2019

Published Date: December 30, 2019

DOI: 10.23 880/ijbp-16000171

*Corresponding author: Sabahelkhier MK, Department of Biochemistry and Molecular Biology, Faculty of Science and Technology, Al-Neelain University, Khartoum, Sudan, Email: mskhalid53@gmail.com

\section{Abstract}

The present study was conducted to detect aflatoxins, namely B1, B2 (Aflatoxins produce blue colour), G1, G2 (aflatoxins produce green colour) and AFM (aflatoxins in milk) in milk, egg, banana and onion collected from three different locations (Bahri, Omdurman and Khartoum) in Khartoum State, Sudan. The result showed that a high level of AFB1 was detected in onion obtained from all locations in Khartoum State. A small amount of AFB2 was detected in egg and banana obtained from the locations. The results showed that all foodstuffs are free from AFG1 and AFG2 but a high level of AFM was detected in milk obtained from all locations in Khartoum State. The results obtained indicated that the presence of such aflatoxins in some of these products may represent a risk to the consumer; therefore it is necessary to know the reasons that led to their spread.

Keywords: AFB1; AFB2; AFGI; AFG2; AFM; Egg; Onion; Banana; Milk

\section{Introduction}

Aflatoxins are group of structurally toxic compounds produced by certain strains of fungi (Asperillus flavus), such fungi produced only B aflatoxins and A parasitic; in addition they produces both $B$ and $G$ aflatoxins. The major aflatoxins are designated B1, B2, G1 and G2 Aflatoxin B is the aflatoxin which produces a blue color under ultraviolet while Aflatoxin G produces the green color. AFM1 produces a blue-violet fluorescence while AFM2 produces a violet fluorescence [1]. Aflatoxins are genotoxic, carcinogenic and immunosuppressive substances, and cause both acute and chronic toxicity [2].

Crop growth and its interaction with beneficiary and pathogenic and/or toxigenic microorganisms vary from year to year, mainly depending on local weather, making the agricultural sector particularly exposed to climate change [3]. These fungal metabolites are important causes of chronic toxicity from exposure via food [4].

These toxins are usually found together in various foods and feeds in various proportion. Aflatoxins M1 and 


\section{International Journal of Biochemistry \& Physiology}

M2 are oxidative metabolic product of aflatoxins B1, and B2 produce by animals and is usually excreted in milk, urine and faces of dairy cattle and other mammalian species that have consumed aflatoxins contaminated food or feed. Aflatoxicol is reductive metabolite of aflatoxins B1 [5]. National dietary surveys are used for monitoring the food consumption and nutrient intakes of population groups and for assessing potential foodborne risks, which arise from the intake of harmful substances such as toxins or microbes, or the excessive intake of natural food components. Food risk assessment is used to characterize the potential adverse effects on health resulting from exposure to food-borne risks over a specified time period [6], in recent years, the idea of risk based food safety management has increased the need for food risk assessment. Risk assessment based food safety measures are designed to reduce risks to a target level [6]. These measures are planned in order to achieve an established level of human health protection. In order to qualify foodborne risks, an exposure assessment, as a part risk assessment, is essential. For exposure assessment, demographically and geographically representative food consumption data is needed. In most countries, Risk analysis is a powerful tool for carrying out science-based analysis and for reaching sound, consistent solutions to food safety problem. The term of risk analysis can promote ongoing improvement in public health and produce a basis for expanding international trade in food. Mycotoxins are toxic secondary metabolites produced by filamentous fungi, most commonly of the genera Aspergillus, Fusarium and Penicillium, other important producers being Claviceps and Alternaria [7].

Several hundred different mycotoxins have been discovered so far, exhibiting different structural diversity, with various chemical and physicochemical properties, but only a few present significant food safety challenges [8]. aflatoxins and ochratoxins are produced by Aspergillus sp., fumonisins, trichothecenes and zearalenone are produced by Fusarium sp., patulin is produced by Penicillium sp. and ergot alkaloids are produced in the sclerotia of Claviceps sp. They are the most frequent occurring mycotoxins with the most severe effects in humans and animals [9].

Mycotoxins remain challenging to classify due to their diverse chemical structures, biosynthetic origins and their production by a wide number of fungal species. A first approach can be to classify them according to their differences in their fungal origin, chemical structure and biological activity. Also the classification can be done according to how frequently they occur and in what amounts. This is a more complicated task because mycotoxin contamination of food and feed depends on environmental and climatic conditions, harvesting techniques, storage conditions and some others factors. Typically, the classification schemes reflect the scientific background of the person doing the categorizing. For clinicians the classification is done depending on the organ they affect: hepatotoxins, nephrotoxins, neurotoxins, immunotoxins. For cell biologists the classification is done according to generic groups such as teratogens, mutagens, carcinogens and allergens. Organic chemists tend to classify mycotoxins according to their chemical structures e.g. Lactones, coumarines, biochemists according to their biosynthetic origins such as polyketides, amino acid-derived, physicians by the illnesses, they cause such as St. Anthony's fire, stachybotrytoxicosis, and mycologists by the fungi that produce them e.g. Aspergillus toxins, Penicillium toxins [10]. The major mycotoxins are aflatoxins (AFs) [11,12], Zearalenone (ZEN) [13] and Ochratoxins (OT) [14].

Extensive investigation of Brazilian peanut meal showed that it contaminated with aflatoxins (Daly, 2000) which had become moldy during transport. Further investigations showed that the peanut meal was heavily contaminated with the organism Aspergillus flavus, hence the name Aflatoxin [15] and that the poultry died from liver cancer since the aflatoxins were highly carcinogenic.

In particular, aflatoxins, had the highest acute and chronic toxicity of all mycotoxins [16]. The topic is of great economic and societal interest both for the quantitative and qualitative effects on crop yield and the impact on the occurrence of mycotoxins [17]. Very low Aflatoxin contamination was reported in the few studies published on wheat [18]. Indeed, new strategies supported by predictions should be adopted [19], such as biological control using a toxigenic A. flavus strains, able to displace the toxigenic populations of the fungus, as largely applied in risk areas in the USA and Africa [20].

The present study aimed to detect the amount of different types of aflatoxins in foodstuffs obtained from three different locations in Khartoum State, Sudan.

\section{Material and Methods}

\section{Materials}

Seventy two samples (4 Foods X 3 locations X 6 samples) namely, Milk; Egg, Onion and Banana were 


\section{International Journal of Biochemistry \& Physiology}

collected from different locations (Khartoum, Omdurman and Bahri) in Khartoum State.

\section{Preparation of Sample}

All samples were collected and kept in polyethylene bags and the milk was put in glass bottles, then they were taken to the laboratory for analysis. All samples were dried and the dry samples were crushed in mortar to a fine powder and put in sterile containers until all chemicals analysis will be started. A serial dilution technique was applied where $1 \mathrm{~g}$ of the sample was diluted in $9 \mathrm{ml}$ peptone water and vortexed sample of $1 \mathrm{ml}$ of this suspension was transferred to sterile petrin dishes mixed with potato dextrose Agar (PDA) at $28^{\circ} \mathrm{C}$ for $3-5$ days. After the incubation period the growing fungal culture were examined micro scenically uing lacto phenol cotton blue (LPCB) stain and classified by reporting the culture characteristics at the face and reverse side of the inoculated petri dishes [20]. Standard solution was prepared by dissolving $0.4 \mathrm{ml}$ of stock standard solution in methanol to produce a concentration of $50 \mathrm{mg} / \mathrm{ml}$ in a $10 \mathrm{ml}$ volumetric flask, other working standard solutions were prepared by diluting this standard solution with methanol to achieve different concentrations of aflatoxins mixtures.

\section{Detection of Aflatoxin}

Extraction, clean up and determination of aflatoxins were done according to the method described by AOAC [21]. Fifty grams of a representative powdered of different type of samples were transferred into a blender Jar, containing $200 \mathrm{ml}$ methanol and $50 \mathrm{ml} 0.1 \mathrm{~N}$ hydrochloric acid and blundered for $3 \mathrm{~min}$ at high speed. The solution was filtered through $24 \mathrm{~cm}$ Whatman No 1 . Filter paper, then $50 \mathrm{ml}$ of the filtrate was transferred into a $250 \mathrm{ml}$ separation funnel, $50 \mathrm{ml}$ of $10 \%$ sodium chloride solution was added and the solution was swirled. Fifty milliliters of hexane was added and the solution was shaken gently for 20 seconds. The two phases were separated and the lower layer was drained into a $250 \mathrm{ml}$ separation funnel and extracted three times with $25 \mathrm{ml}$ of dichloromethane. The dichloromethane extracts were combined and concentrated to approximately $2 \mathrm{ml}$. The concentrated extract was carefully transferred into a silica gel chromatography column and washed with $30 \mathrm{ml}$ of ether: hexane solution $(3: 1)(\mathrm{v} / \mathrm{v}) 2.0 \mathrm{ml}$ of the dichloromethane extract was poured into the column and the beaker was washed with $0.5 \mathrm{ml}$ of dichloromethane. The column was cleaned with $25 \mathrm{ml}$ of benzene: acetic acid $(9: 1)(\mathrm{v} / \mathrm{v})$, then $30 \mathrm{ml}$ of ether. Aflatoxins (AFs) were eluted from the column with $100 \mathrm{ml}$ of dichloromethane: acetones $(90: 10)(\mathrm{v} / \mathrm{v})$, the solvents were evaporated. To derivative the AFs, $200 \mu \mathrm{l}$ hexane and $50 \mu$ l triflouroacetic acid (TFA) were added. The mixture was shaken vigorously using a Vortex for 30 seconds and left to stand for $5 \mathrm{~min} .1 .95 \mathrm{ml}$ of acetonitrile; water (1:9) $(\mathrm{v} / \mathrm{v})$ was added; the mixture was shaken for 30 seconds and left for $10 \mathrm{~min}$ to separate. The lower aqueous layer was collected by automatic pipette and used for HPLC analysis; for the blank test, similarly, a working standard mixture was derivatived. The HPLC conditions used were Supercoil LC 18 column , 150 x 4.6 mm internal diameter (I.D) , 5 micron particle size; oven temperature $40{ }^{\circ} \mathrm{C}$, fluorescence detector at excitation $360 \mathrm{~nm}$ and emission $476 \mathrm{~nm}$, mobile phase consisted of water : acetonitrile: methanol (700:170:170) was used. The flow rate of the mobile phase was maintained at 1.0 ml min-1 and then volume of sample solution was injected about20 $\mu$ l.

\section{Statistical Analysis}

Statistical analysis was performed using SPSS package for windows version 21.0 Data are expressed as Mean \pm SD, one way ANOVA and T -test were used to analyze differences among groups.

\section{Results and Discussion}

Table 1 indicated that calculate values of AFB1 (Aflatoxin bluish) in Bahri, Khartoum and Omdurman in onion were $9.58 \pm 1.12,3.80 \pm 0.76$ and $6.75 \pm 1.48 \mathrm{ppb}$, respectively. These findings indicated that the AFB1 are found in three locations only for anion crop, but it is still observed that calculated value of FB1 are not detect in Egg, Banana and Milk in three locations in Khartoum State. However, the calculated value of AFB1 in Bahri is highly significant $(\mathrm{P}<0.01)$ compared with maximum residue limit value (MRL) reported by Amendment Codex standard [21], whereas calculated value of AFB1 in Khartoum location is significantly low $(\mathrm{P}<0.05)$ compared with maximum residue limit value (MRL) reported by Amendment Codex standard [22], While in Omdurman location is high than those findings by Amendment Codex standard [22]. The result obtained in all location (Bahri, Khartoum and Omdurman) is still lower than that reported by EFS [23]. The calculated value of AFB2 (Aflatoxin bluish) in egg and Banana for Bahri location was $1.78 \pm 0.12$ and $2.70 \pm 0.32 \mathrm{ppb}$, respectively. While that of AFB2 in Khartoum for Banana was $2.18 \pm 0.67 \mathrm{ppb}$, onion and milk in all locations. These findings are lower than those values reported by Amendment Codex standard, EFS [22,23]. Therefore, the 


\section{International Journal of Biochemistry \& Physiology}

egg, banana, onion and milk are less contaminated with AFB2 in three locations. Contamination of milk, egg, onion and banana with AFB1 and AFB2 can cause potential carcinogenic effects if ingested even in small amounts [24].

It is also observed that AFG1 and AFG2 (Aflatoxin greenish) in Egg, Banana, Onion and milk are not detected in three locations. These results are reflecting that Egg, Banana, Onion and milk were free from AFG1 and AFG2; this might be due to following the proper hygienic operations during handling, transport and storage of those egg, milk, onion and banana. Therefore, those foods in three Locations in Khartoum state was less contaminated with AFG1 and AFG2.

It is still observed that the calculated value of AFM (aflatoxin in milk) for the milk in three locations (Bahri, Khartoum and Omdurman) was $2.27 \pm 0.69,4.35 \pm 0.69$ and $3.48 \pm 0.62 \mathrm{ppb}$, respectively. These results are indicated that calculated value of AFM for milk in three locations was highly significant than those values reported by AOAC [21]. It is also clearly observed that AFM are not detected in egg, banana and onion in three locations. This might be climate Change, highlighting how changes in temperature, humidity, rainfall and carbon dioxide production impact on fungal behaviour and consequently on mycotoxin production [24].

The panel estimates that raising the maximum level could increase the risk of aflatoxin-induced cancers for consumers of peanuts and peanut-based processed products [19].

\begin{tabular}{|c|c|c|c|c|c|c|c|c|c|}
\hline Aflatoxin Types & $\begin{array}{c}\text { AFB1 } \\
\text { CV }\end{array}$ & AFB2 & MRL & MD & AFG1 & AFG2 & AFM & MRL & MD \\
\hline Bahri & & & & & & & & & \\
\hline Egg & ND & $1.78 \pm 0.12$ & 5.0 & $-3.22^{*}$ & ND & ND & ND & & \\
\hline Banana & ND & $2.70 \pm 0.32$ & 5.0 & $-2.30^{*}$ & ND & ND & ND & & \\
\hline Onion & $9.58 \pm 1.12$ & ND & 5.0 & $4.58^{* *}$ & ND & ND & ND & & \\
\hline Milk & ND & ND & 5.0 & ---- & ND & ND & $2.27 \pm 0.69$ & 0.50 & $1.77^{* *}$ \\
\hline Khartoum & & & & & & & & & \\
\hline Egg & ND & ND & 5.0 & ----- & ND & ND & ND & & \\
\hline Banana & ND & $2.18 \pm 0.67$ & 5.0 & $-2.82^{*}$ & ND & ND & ND & & \\
\hline Onion & $3.80 \pm 0.76$ & ND & 5.0 & $-1.2^{*}$ & ND & ND & ND & & \\
\hline Milk & ND & ND & 5.0 & ----- & ND & ND & $4.35 \pm 0.69$ & 0.50 & $3.85^{* *}$ \\
\hline Omdurman & & & & & & & & & \\
\hline Egg & ND & $1.38 \pm 0.57$ & 5.0 & $-2.82^{*}$ & ND & ND & ND & & \\
\hline Banana & ND & $4.32 \pm 0.48$ & 5.0 & $-2.68^{*}$ & ND & ND & ND & & \\
\hline Onion & $6.75 \pm 1.48$ & ND & 5.0 & $1.75^{*}$ & ND & ND & ND & & \\
\hline Milk & ND & ND & 5.0 & ----- & ND & ND & $3.48 \pm 0.62$ & 0.50 & $2.98^{* *}$ \\
\hline
\end{tabular}

Table 1: Aflatoxin concentration (ppb) of products collected from different sites in Khartoum State and correlated with the maximum residue limit (MRL) [25].

CV (Calculated value), MD (Mean difference), and ND(Not detected).. Values are means of 6 samples \pm SD. ${ }^{* *} \mathrm{P}<0.01, *$ $\mathrm{P}<0.05$. Mean difference $=$ calculated value- maximum residue limit $(\mathrm{MRL})[22]$.

\section{Conclusion}

The results reflected that AFB1 in onion was observed in three locations in Khartoum State, in addition the value obtained is high. AFB2 for egg and banana in three locations are detected, except AFB2 for egg in Khartoum is not detected.AFG1 and AFG2 for egg, milk, onion and banana in three location were not detected, therefore, egg, milk, onion and banana are free from AFG1 and AFG2. In addition a high level of AFM in milk was detected in three locations in Khartoum State.

\section{References}

1. Pakistan Society for Horticultural Science (PPSHS) (2016) Production Challenges and Food Security. $2^{\text {nd }}$ International Conference on Horticultural Sciences, Institute of Horticultural Sciences, University of Agriculture, Faisalabad, Punjab, Pakistan. 


\section{International Journal of Biochemistry \& Physiology}

2. Battilani P, Toscano HJ, Van der Fels-Klerx, Moretti A, Camardo LM, et al. (2016) Aflatoxin $\mathrm{B}_{1}$ contamination in maize in Europe increases due to climate change. Sci Rep 6: 1-7.

3. Moore FC, Lobell DB (2015) The fingerprint of climate trends on European crop yields. Proc Natl Acad Sci 112(9): 2670-2675.

4. De Boevre M, Graniczkowska K, De Saeger S (2015) Metabolism of modified mycotoxins studied through in vitro and in vivo models: an overview. Toxicol Lett 233(1): 24-28.

5. Bakirici I (2001) A study on the occurrence of aflatoxin MI in milk and milk products produced in Van province of Turkey. Food Control 12(1): 47-51.

6. FAO/WHO (2006) The Use of microbiological risk assessment outputs to develop practical risk management strategies: Metrics to improve food safety. Report of Joint FAO/WHO meeting in collaboration with the German Federal Ministry of Food, 35 Agriculture and Consumer Protection. Kiel, Germany, pp: 3-7.

7. Bhat R, Rai RV, Karim AA (2010) Mycotoxins in food and feed: present status and future concerns. Comprehensive Reviews in Food Science and Food Safety 9(1): 57-81.

8. Cole RJ, Cox RH (1981) Handbook of toxic fungal metabolites, Academic Press, New York.

9. Richard JL, Bennett GA, Ross PF, Nelson PE (1993) Analysis of naturally occurring mycotoxins in feed stuffs and food. J Anim Sci 71(9): 2563-2574.

10. Scott-Craig JS, Panaccione DG, Pocard JA, Walton JD (1992) The multifunctional cyclic peptide synthetase catalyzing HC-toxin production in the filamentous fungus Cochliobolus carbonum is encoded by a 15.7 kb open reading frame. J Biol Chem 267(36): 2604426049.

11. Vargas J, Due M, Frisvad JC, Samson RA (2007) Taxonomic revision of Aspergillus section Clavati based on molecular, morphological and physiological data. Stud Mycol 59: 89-106.

12. Klich MA (2002) Identification of common Aspergillus Species. Spi (Edn.), Amer Society for Microbiology, Ponson and Loorjen, Wegeningen, The Netherland, pp: 1-107.
13. Hussein HS, Brasel JM (2001) Toxicity, metabolism and impact of mycotoxins on humans and animals. Toxicology 167(2): 101-134.

14. Zinedine H (2010) Ochratoxin A in Morocan Foods: Occurrence and Legislation. Toxins (Basel) 2(5): 1121-1133.

15. Smith JE (1997) aflatoxins. In: D'Mello JFP (Ed.), Handbook of Plant and Fungal Toxicants. CRC Press, New York, pp: 269-285.

16. Flores-Flores ME, Lizarraga E, de Cerain AL, GonzalezPenas E (2015) Presence of mycotoxins in animal milk: A review. Food Control 53: 163-176.

17. Magan N, Medina A, Aldred D (2011) Possible climate-change effects on mycotoxin contamination of food crops pre- and postharvest. Plant Pathol 60(1): 150-163.

18. Alkadri D, J Rubert, A Prodi, A Pisi, Manes J, et al. (2014) Natural co-occurrence of mycotoxins in wheat grains from Italy and Syria. Food Chem 157: 111-118.

19. Joint FAO/WHO Expert Committee on Food Additives (JECFA) (2016) JECFA is an international scientific expert committee. Food and Agriculture Organization of the United Nations (FAO), WHO.

20. Hayat S, Idris A (2000) Soil microbiology Practical. Univ. Printing, Khartoum, pp: 24-25.

21. AOAC (1995) Official methods of analysis. 15 ${ }^{\text {th }}$ (Edn.), Association of Official Analytical Chemists, Natural poisons, mycotoxins.

22. Amendment Codex standard (2014) General standard for contaminants and toxins in food. CODEX STAN, 193-1995.

23. Europeans Food Safety Authority (EFS) (2018) Aflatoxin in Food.

24. Europeans Food Safety Authority (EFS) (2017) Aflatoxin in Food.

25. Atehnkeng J, Ojiambo PS, Cotty PJ, Bandyopadhyay R (2014) Field efficacy of a mixture of atoxigenic Aspergillus flavus Link: Fr vegetative compatibility groups in preventing aflatoxin contamination in maize (Zea mays L.). Biol Control 72: 62-70.

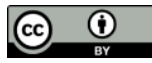

